\title{
Languages, Fees and the International Scope of Patenting
}

\author{
DietMar HaRHofF, KARIN HOISL, \\ Bruno van Pottelsberghe de la Potterie
}

Discussion Paper 2009-06

March 2009

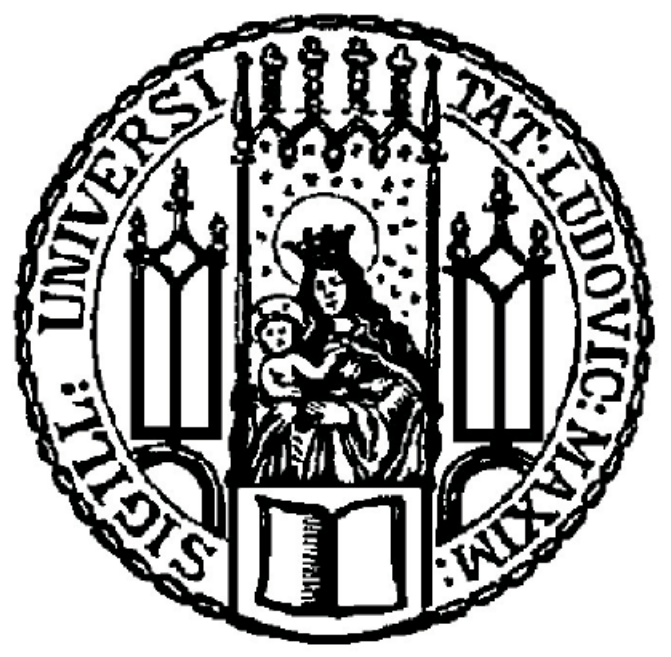

LMU

Munich School of Management

University of Munich

Fakultät für Betriebswirtschaft

Ludwig-Maximilians-Universität München

Online at http://epub.ub.uni-muenchen.de/ 


\title{
Languages, Fees and the International Scope of Patenting
}

\author{
Dietmar Harhoff $^{\text {ab }}$, Karin Hoisl ${ }^{\mathrm{a}}$, Bruno van Pottelsberghe de la Potterie* bcd \\ ${ }^{a}$ Institute for Innovation Research, Technology Management and \\ Entrepreneurship (INNO-tec), University of Munich (LMU) \\ ${ }^{b}$ Centre for Economic Policy Research (CEPR), London, UK \\ ${ }^{c}$ Université Libre de Bruxelles (U.L.B.) - SBS-EM - \\ Solvay SA Chair of Innovation, ECARES \\ ${ }^{d}$ Bruegel, Brussels
}

\begin{abstract}
This paper analyzes firms' choices regarding the geographic scope of patent protection within the European patent system. We develop an econometric model at the patent level to quantify the impact of office fees and translation costs on firms' decision to validate a patent in a particular country once it has been granted by the EPO. These costs have been disregarded in previous studies. The results suggest that both translation costs and fees for validation and renewals have a strong influence on the behavior of applicants. The estimates are then employed to simulate the impact of the London Protocol, a recent policy reform which reduces translation requirements in the European patent system. National validations of patents granted by the EPO are estimated to increase by $29 \%$.
\end{abstract}

JEL Classification: $\quad \mathrm{O} 30, \mathrm{O} 31, \mathrm{O} 38, \mathrm{O} 57$

Keywords: patents, patent fees, patent validation, renewal fees, translation costs

\section{Acknowledgement}

The authors thank Nicolas van Zeebroeck for developing the methodology for identifying validations and for constructing the dataset. The authors would like to thank the EPO for providing access to the patent renewal data used in this paper. DH acknowledges support by the Deutsche Forschungsgemeinschaft (DFG) within its SFB/TR 15 collaborative research programme (Project C2). Furthermore, the authors would like to thank Georg von Graevenitz, seminar audiences at KU Leuven, ZEW Mannheim, in particular, Alberto Galasso, and the $3^{\text {rd }}$ EPIP Conference for helpful comments. 


\section{Introduction}

Recent developments in patenting activity are the subject of a growing literature. Since the mid-1990s scholars have focused on various aspects of patenting behavior. One line of exploration focuses on the incentives that drive economic agents to rely on the patent system (e.g., Cohen et al. 2000, Arundel 2001, Peeters and van Pottelsberghe 2006, Blind et al. 2006 and von Graevenitz et al. 2008), and on potential implications of their behaviour for the effectiveness of the patent system. Another line of research focuses on the filing and drafting strategies of applicants when applying for a patent. In this literature, researchers have focused on choices regarding the number of claims (van Zeebroeck et al. 2006; Archontopoulos et al. 2007), the quality of patent drafting (Stevnsborg and van Pottelsberghe 2007), and the filing of multiple patents based on few underlying priority filings, as in the case of divisional applications (Harhoff 2006).

However, in both of these literatures, the determinants of the international scope of patent protection have so far been neglected. While geographical scope is frequently used as an indicator of patent value (Putnam 1996), its determinants have so far not been identified explicitly. To the best of our knowledge, only a few studies have focused on the drivers of international patenting. Among them are Bosworth (1984), Eaton and Kortum (1996), Porter and Stern (2000), and Eaton et al. (2004). The cost structures considered in these studies have been rather simple - for example, none of them have taken into account the role of post-grant fees related to the validation of patents in multiple jurisdictions or translation costs as potential determinants of the geographical extension of patent protection. Even recent studies (e.g., Deng 2007) using a renewal cost approach to identify the value of EPO-granted patents have disregarded the issue of translation and validation costs although these can easily be of the same order of magnitude as cumulative renewal fees.

The objective of this paper is to contribute to the literature with an in-depth analysis of the geographical scope of protection. The European patent system provides an excellent setting for understanding the drivers of international patenting strategies, since it imposes rather heterogeneous cost regimes on patent applicants. Once a patent is granted by the EPO, the applicant has the option, but not the obligation to validate the patent in any of the countries for which patent protection was requested. Possibly for each country, the applicant faces a one-time validation fee and translation costs if he wishes to validate the grant in the respective jurisdiction, and a sequence of country-specific renewal payments thereafter.

An empirical model of validation behaviour is tested with a unique dataset comprised of all patents that were granted by the EPO in 2003. Our multivariate analysis aims at 
understanding the determinants of patent validation in a given country at the level of individual patents. The main advantage of this empirical approach is that it allows quantifying the impact of fees and translation costs on the behaviour of applicants, taking the observable characteristics of the patent application into account. ${ }^{1}$ The role of fees in patent systems has been neglected in the past, and the role of translation costs is currently the subject of an intense debate regarding reforms in the European patent system. The recently ratified London Protocol $^{2}$ which results in drastically reducing previous translation requirements is a key element of this debate. Under this reform, translation requirements have been lowered significantly, but the impact on the demand for validations has not been quantified in any study. This paper develops a framework which allows us to analyze the impact of such reform measures in quantitative terms.

We model an applicant's decision to seek patent protection for a given patent in one of the European Patent Convention (EPC) member states once the grant decision by the EPO has been made. Our empirical results suggest that the size and the wealth of the origin and destination countries significantly affect the probability to observe a patent validation. These determinants reflect the benefits that a particular applicant from one country will enjoy from patenting in another EPC country. The geographical distance between countries also plays an important role - costs of transportation are still present and limit the benefit of a patent, since the world is not "completely flat" (Friedman 2006). The costs of translating EPO-granted patents into different European languages and the level of renewal fees affect the probability of patent validation negatively. The results support the notion that cost reductions are likely to have a strong impact on patent validations within Europe. Policy simulations based on the estimated parameters predict a substantial increase in validations as a consequence of reduced translation requirements due to the so-called London Protocol.

The paper is structured as follows. In the next section we discuss the institutional context of the European patent system and develop the hypotheses to be tested. Section 3 describes the data set, the construction of the dependent and explanatory variables and the econometric

1 In a companion paper (Harhoff et al. 2007) we rely on a complementary approach, analyzing the validation behaviour at the aggregate level of country-to-country patent flows.

2 The London Agreement, which was signed in London in October 2000, aims at reducing the costs for EP patents. The Parties to the London Protocol agreed to entirely or largely abolish the requirement for translations of the European patent specification. This means that applicants will no longer have to file a translation of the specification of a granted patent for each EPC member state in which they want patent protection. In EPC member states, which are Party to the London Agreement, patents can be filed in one of the three official languages of the EPO (i.e. German, English or French). EPC member states that have not yet signed the London Agreement still require a translation of the specification into one of their official languages. See http://www.epo.org/patents/law/legislative-initiatives/london-agreement.html (accessed on January 4, 2008). 
framework. Descriptive statistics are discussed in section 4. The results of the multivariate tests are presented and interpreted in section 5. Section 6 concludes.

\section{Institutional Background and Hypotheses}

The EPO grants patents for each of the signatory or accession states to the European Patent Convention (EPC). Currently, 35 states have signed the EPC. ${ }^{3}$ Applications may be filed directly at the EPO (as first filings) or be forwarded to the EPO within the priority year after having been filed as a priority application in a national patent office (NPO), ${ }^{4}$ Then, at the latest after one year (under the European Patent Convention ${ }^{5}$ (EPC)) or 31 months (under the Patent Cooperation Treaty ${ }^{6}$ (PCT)), the application may be transferred to the EPO. Historically, the EPO examination process has taken slightly more than 4 years (Harhoff and Wagner 2006 and van Zeebroeck 2007b).

The EPC states in which the applicant would like to receive patent protection have to be designated by the applicant. The designation of states is subject to the payment of a designation fee. The term for designating EPC member states expires six months after the European Patent Bulletin announces the publication of the search report (Article 79 (2) EPC). However, contracting states "may be withdrawn at any time up to grant of the European patent" (Article 97 (3) EPC). ${ }^{7}$ Before July 1999, applicants were obliged to pay a designation fee for each designated contracting state (Article 2 (2), (3) Rules relating to Fees). In December 1998, the EPO amended its "Rules relating to Fees". ${ }^{8}$ Effective as of July 1, 1999 "designation fees being deemed paid for all contracting states upon payment of seven times the amount of this fee" (amended Article 2 (3) Rules relating to Fees). ${ }^{9}$ Thus, with the payment of designation fees for seven countries, it became possible to designate all of the 35 EPC countries.

3 See the Appendix, Table A.1 for a list of signatory and accession countries and the date of entry into the European system.

4 Cf. Guellec and van Pottelsberghe (2007) and Stevnsborg and van Pottelsberghe (2007) for an in-depth description of the various filing routes which may lead to an application at the EPO.

5 The European Patent Convention (EPC) signed in Munich in 1973 is a contract constituting the European Patent Organisation and providing an independent legal system under which European patents are to be granted. The EPC came into force in 1977 and the European Patent Office (EPO) was founded in the very same year. On June 1, 1978, the first European patent application was filed with the EPO. Today, the EPC has 35 member states (the Appendix contains a list of the 35 member states (Table A.1)). See http://www.epo.org/patents/law/legal-texts/html/epc/1973/e/contents.html (accessed on January 4, 2008).

6 The Patent Cooperation Treaty was signed in Washington in 1970 and entered into force in 1978. By filing a patent application under the PCT, it is possible to obtain protection in up to 138 PCT contracting states (see http://www.wipo.int/pct/en/treaty/about.htm and http://circa.europa.eu/irc/dsis/coded/info/data/coded/en/ gl003819.htm (accessed on January 4, 2008).

7 See http://www.epo.org/patents/law/legal-texts/html/epc/1973/e/ar79.html, accessed May 3, 2008.

8 See http://www.european-patent-office.org/news/pre_oj/fees_6_99_e.htm, accessed May 3, 2008.

9 See http://documents.epo.org/projects/babylon/eponet.nsf/0/A7E3392B2D7E2D7AC125738A003DA6FC/ \$File/rules_relating_to_fees_071213.pdf, accessed May 3, 2008. 
The choice of the regional scope of patent protection is effectively made by the applicant once the patent has been granted. At that point the applicant must select the EPC countries in which he would like to receive patent protection, eventually have the patent translated into the official languages of these countries, and pay the validation fees as well as the renewal fees for each year of protection. ${ }^{10}$ The setup is therefore appropriate for assessing the sensitivity of applicants to marginal increases of fees and transactions costs.

In what follows, we take into account the extant analyses of firms' patenting behavior in order to derive hypotheses regarding the potential determinants of the geographical scope chosen by firms. One of the early studies on the geographical scope of patent protection is provided by Slama (1981). The author investigates the determinants of international patent application flows at the country level using German patent application data between 1967 and 1978 . Results show a positive elasticity of filing flows w.r.t. the GDP of applicant countries. Bosworth (1984) uses UK patent data from 1974 to assess the factors influencing the decision to transfer technology across borders. The empirical analysis at the firm-level reveals a positive relationship between the GDP of the destination country and the decision to apply for patent protection in this country. The GDP of a country reflects the size of its economy and also its wealth (GDP per capita). The two studies suggest that the GDP of both the applicant's and the target country have a role to play in the validation decision. Once GDP is accounted for, Slama (1981) does not find any significant influence of the population of the destination and the source country on patent application flows between two countries. Macroeconomic studies generally attach great value to the population of country pairs as a factor explaining trade flows between countries (e.g., Tinbergen 1962, Geraci and Prewo 1977, and Abrams 1980). The test performed by Slama (1981) and Bosworth (1984) and the results of the trade literature thus lead us to put forward the following hypotheses:

H.1a: $\quad$ The GDP per capita of the destination country (i.e. country in which a patent is to be validated) positively influences the probability of a patent validation.

H.1b: The GDP per capita of the origin country (i.e., the country of residence of the applicant) positively influences the probability of a patent validation.

H.2a: The number of inhabitants of the destination country positively influences the probability of a patent validation.

10 This fragmentation of the European patent system has been criticized for years by the business sector, as it induces a high managerial complexity and is associated with relatively high cumulative fees and translation costs. Cf. van Pottelsberghe and François (2009) and van Pottelsberghe and Mejer (2008) for simulations of total patenting costs in the European patent system. International comparisons show that even after the London Agreement the costs of patenting are at least four times higher in Europe than in the US. 
H.2b: $\quad$ The number of inhabitants of the origin country positively influences the probability of a patent validation.

These hypotheses suggest that both the wealth and the size of the origin and the destination countries substantially affect the probability of observing a validation of a patent originating in a home country in the respective destination country. As a measure of the relative wealth of the origin country, we use GDP per capita. Applicants from richer countries have on average more income at their disposal to file patents abroad. The wealth of the destination country is assumed to attract more validations as demand conditions in the respective market are more attractive for firms. The destination country's population should also positively affect the validation behavior as a large market is certainly more attractive than a smaller one, even after accounting for GDP per capita. The effect of the size of the applicant's country (origin country) on validations is less straightforward, and possibly negative. Indeed, smaller countries (with a smaller domestic market) may be characterized by a higher probability to validate patents abroad than larger countries (with large domestic markets).

So far, little research has been done on the influence of costs and fees on the patenting behavior of firms. ${ }^{11}$ Pakes and Schankerman (1984) and Schankerman and Pakes (1986) have shown that renewal decisions are affected by the level of renewal fees. A few other studies have investigated the role of patent fees. One of the first studies to analyze the influence of non-maintenance patenting costs on the decision to apply for a patent was conducted by van Pottelsberghe and François (2009). The authors compare the costs of patenting ${ }^{12}$ in the US, Japanese and European patent systems to assess whether patenting costs have an impact on the demand for patents. Results show that in 2003 the costs for a patent designating 13 EPC member countries is 4 to 8 times (depending on the duration of patent protection) more expensive compared to the US. Taking the number of claims of a patent as well as the market size of the selected member states into account, the data provide graphical evidence that the demand for patents may be price elastic, i.e., the demand for patents may be partly explained by differences in market size and differences in fees, as illustrated by their " $3 C$ " index (the cost per claim per capita). Further evidence on the role of fees is provided by de Rassenfosse

11 de Rassenfosse and van Pottelsberghe (2007) investigate the role of priority filing fees at national patent offices and van Pottelsberghe and François (2009) compare the fees and translation costs in Japan, the United States and Europe. Harhoff et al. (2006) analyse the extent to which fees explain validation flows at the country level using a gravity model. de Rassenfosse and van Pottelsberghe (2008) provide time series evidence on the potential impact of cumulated fees at the USPTO, JPO and EPO on the demand for patents. All these studies obtain results that suggest that fees influence the patenting behaviour of applicants.

12 The following cost categories were taken into account: (1) procedural costs (filing fee, search fee, fees for designating states, examination fee, claim tax, renewal fees for the years 3 and 4 after application at the EPO and validation costs), (2) estimated translation costs, and (3) estimated costs for external services (professional services, attorneys, etc.). 
and van Pottelsberghe (2007), who show that priority filing fees at national patent offices have a negative and significant impact on the number of patent applications. However, the demand for first filings at national offices is determined by a rather complex set of factors. An alternative and potentially more telling experiment would be to analyse the patents already granted by one institution and then analyse in which countries they are then taken for validation. The present study pursues this approach and uses the validation phase following the EPO grant as the research setting.

The research design adopted in the present paper allows us to identify the impact of post-grant fees and translation costs on the patenting behaviour of applicants. Post-grant fees (i.e., translation costs, validation fees and fees for maintaining patent protection for the years 4 to 6 after application at the EPO) are of particular importance for our analysis, since we assume that these costs drive the validation decision of applicants and consequently are important determinants of the scope of protection. Moreover, these costs are marginal in the sense that at the point of decision-making all examination and application fees are sunk, and the receipt of the national patent only depends on the costs considered here. We also take early renewal fees into account because they represent the expenses that an applicant has to be ready to pay when extending patent protection once the patent has been validated in the respective country. We do not model renewal behavior fully, but use the renewal fees requested by the national patent offices from years 4 to 6 after the application date at the EPO as a measure of these costs.

Assuming that applicants rationally decide about the regional scope of their patent portfolio, the following hypotheses relating to fees, translation and early renewal costs are put forward:

H.3a: $\quad$ The probability of patent validation in an EPC country decreases with an increase in relevant translation costs.

H.3b: The probability of patent validation in an EPC country decreases with an increase in the country-specific validation fees.

H.3c: $\quad$ The probability of a patent validation in an EPC country decreases with an increase in the country-specific early renewal fees. 


\section{Data Source and Sample}

Data about filing and grant dates, the country of origin of the priority filings, the language of the official proceedings at the EPO and the technical classification of the patent application (IPC classes) were extracted from the EPO's EPASYS database as of January 15, 2006. Data on the lapse of patents into the public domain was obtained from the EPASYS database as of December 2006. The data were supplemented with information on renewal payments, which were received from the EPO post grant system as of December 2006. The empirical analysis relies on 53,904 patents granted in 2003 by the EPO and validated in at least one EPC member state. Granted patents which had not been validated in any of the EPC member states were excluded from the dataset. ${ }^{13}$

Patent validation - After grant, a European (EP) patent has to be validated in each state for which protection is sought, i.e., the patent has to be converted into a bundle of patents having the same legal status as patents granted through the national procedures. ${ }^{14}$ In general, this requires the filing of a translation of the patent specification, and the payment of national validation or publication fees within a specified term (Art. 65(1) EPC). ${ }^{15}$ However, a validation is also possible without filing a translation in the event the language of the official proceedings at the EPO is (one of) the official language(s) of the validation country. ${ }^{16}$ Furthermore, payment of a validation fee is not required in some countries, such as Switzerland and Belgium.

The patent validation variable is defined as a dummy variable, taking the value one if a patent (granted by the EPO) of applicant country A is validated in country B, and zero otherwise. ${ }^{17}$ We infer the validation status from our data, assuming that a patent has been validated in a

1359,992 patents were granted by the EPO in 2003, but 6,088 (or 10\%) were not included in the dataset because they had not been validated in any of the EPC countries (the patent was withdrawn by the applicant after the decision to grant by the EPO).

14 Cf. http://www.epo.org/patents/Grant-procedure/Filing-an-application/European-applications/nationalvalidation.html (accessed on August 21, 2007).

15 Cf. http://www.european-patent-office.org/legal/epc/e/ar65.html (accessed on August 21, 2007). For a detailed description of the EP grant and validation procedure, see Harhoff et al. (2007).

16 An EP patent application must be filed in one of the official languages of the EPO, i.e. English, German or French, the so called procedural languages. Applications filed in other languages have to be translated into one of the three official languages within a term of three months. See http://www.epo.org/patents/Grantprocedure/Filing-an-application.html (accessed on August 22, 2007).

17 The 20 Applicant countries include:: Austria (AT), Australia (AU), Belgium (BE), Canada (CA), Switzerland (CH), Germany (DE), Denmark (DK), Spain (ES), Finland (FI), France (FR), United Kingdom (UK), Ireland (IE), Israel (IL), Italy (IT), Japan (JP), Korea (KR), The Netherlands (NL), Norway (NO), Sweden (SE), USA (US) (selection criteria: minimum of 100 patents granted in 2003). The 17 countries of validation include: Austria (AT), Belgium (BE), Switzerland (CH), Cyprus (CY), Germany (DE), Denmark (DK), Spain (ES), Finland (FI), France (FR), United Kingdom (UK), Greece (GR), Ireland (IE), Luxembourg (LU), Monaco (MC), The Netherlands (NL), Portugal (PT), and Sweden (SE). Italy (IT) is not included due to the lack of information on validations in Italy. Broad estimates by the EPO suggest that 30 to 40 percent of the patents granted by the EPO are generally validated in Italy. 
given country if $(i)$ renewal fees are paid for the patent to the national patent office of the country and/or (ii) the patent lapses in the given country. In cases where patents lapsed within one year after grant (in all validation countries), the patents were considered as lapsed $a b$ initio and were removed from the dataset. This is equivalent to assuming that these patents had never been validated in any country. ${ }^{18}$

GDP per capita and population - Annual data on GDP in current prices (US dollars in billions) and the population of the different countries in million capita were obtained from the World Economic Outlook Database as of September 2006. The data are published by the International Monetary Fund. ${ }^{19}$ GDP per capita is taken as a proxy for the wealth of a country. The population variable is used as a proxy for the market size of a country.

Physical distance between capital cities - The physical distance between the capital cities of the applicant and the validation country was provided by Kristian Skrede Gleditsch, Department of Government, University of Essex. ${ }^{20}$

EPC membership duration (validation country) - The average number of years of EPC membership of the validation countries was obtained from the homepage of the EPO. ${ }^{21}$ The variable is included in the regression to test whether the duration of EPC membership reflects learning effects. As the transfer rate of domestic priority filings to the EPO increases with EPC membership (de Rassenfosse and van Pottelsberghe, 2007), one may expect that this duration also affects the probability that a patent is validated in a particular country.

Region of the applicant - Four dummy variables characterize the location of the applicants' home countries:

- US applicant

- Japanese applicant

- other non-European applicant: AU, CA, IL, KR

- European applicant: AT, BE, CH, DE, FR, GB, IE, NL, DK, FI, NO, SE, ES, IT

The latter forms the reference group. These regional dummies are used as additional variables to account for unobserved heterogeneity between applicants from these country groups.

Number of claims at grant - To account for the voluminosity of a patent specification, the number of claims at the time of the grant is included in the regression. We treat the number of

18 When the lapse and renewal data sources contained conflicting results $(0.66 \%$ of the cases) information on patent lapses were preferred over renewal information. The decision to prefer information on patent lapses was suggested by an EPO expert.

19 Cf. http://www.imf.org/external/pubs/ft/weo/2006/02/data/index.aspx (accessed on April 5, 2007). Since Monaco was missing in this database, GDP data were supplemented with data extracted from the United Nations Statistics Division (see http://unstats.un.org/unsd/snaama/dnllist.asp (access on April 5, 2007)). GDP data for Monaco were estimated based on the assumption that the level of GDP per capita is proportional to that of Luxembourg.

20 Cf. http://privatewww.essex.ac.uk/ ksg/mindist.html (accessed on March 30, 2007).

21 Cf. http://www.epo.org/about-us/epo/member-states.html (accessed on March 30, 2007). 
claims as a proxy for the overall number of pages that need to be translated, and thus as the scale factor in translation costs. Archontopoulos et al (2007) show that there is a strong correlation between the number of pages included in a patent and the number of claims it contains.

Citations - It is likely that more relevant patents are validated in more EPC member states. We therefore include an additional variable accounting for the potential importance of the patent. In particular, we use the number of citations as a rough proxy for a patent's relevance (Gambardella et al. 2008). Since patents that are validated in many countries are more visible and may, therefore, also be more frequently cited by patent examiners, we employ the number of citations a patent application received within 3 years after publication. The end of this time span will usually precede the grant of the patent so that we will avoid endogeneity problems.

Patent portfolio (5 years) - The number of patents granted to the applicant(s) within 5 years before the grant of the focal patent is also used in the probit model. This 'portfolio size' variable accounts for the resources available to the applicants as well as to proxy their patenting experience.

Translation costs - To validate a patent in a particular country, the document has to be translated from one of the EPO's official three languages (German, French, English) into the official language of the target country. These translations are generally provided by foreign patent attorneys or translation services. Since we do not have direct measures of translation costs, we develop various proxies. ${ }^{22}$ Irrespective of the country of origin, some target countries have languages that are perceived as difficult - or costly - to translate. The validation countries were therefore classified into three groups according to the level of assumed translation costs. Specifically, translations into Nordic languages and Greek are usually more expensive than translations into languages spoken in central or southern Europe. The lowest translation costs (if any) arise for countries which have German, English, or French as one of their official languages. The following three dummy variables were created:

- low translation costs: DE, FR, UK, AT, CH, BE, IE, MC, LU

- medium translation costs: ES, PT, NL

- high translation costs: SE, DK, FI, GR, CY

In some cases, translations are not required and translation costs are thus equal to zero - we will use these cases as our reference group. A translation does not have to be filed if the application and the validation country share a common language, which is the case for $9 \%$ of

\footnotetext{
${ }^{22}$ Contrary to our expectations, it proved difficult to find consistent data on translation costs across countries. We therefore approximate these costs in terms of country groups and language distances. Cf. van Pottelsberghe and Mejer (2008) for an approximation of translation costs requested by 11 European patent attorneys.
} 
the country pairs. Similarly, no translation is required for the validation countries which have a language similar to the languages of the official proceedings at the EPO. As a first approximation for the extent of translation costs, we use the three dummy variables for low, medium and high translation costs (relative to the reference group of validations not requiring any translations).

Language distance matrix - The "Dyen Matrix of Linguistic Distances" (Ginsburgh et al. 2005 ) is used to generate a more fine-grained measure of translation costs. The matrix is based on data collected by Dyen in the 1960s. In particular, Dyen collected words used in 95 Indo-European languages and dialects (Dyen et al. 1992). These speech varieties were classified into 'cognate classes'. The distance measure was calculated as the percentage cognate between language $l$ and language $m$ :

$$
\text { language distance } \text { DYYN }=\frac{n_{l m}}{\left(n_{l m}^{0}+n_{l m}\right)}
$$

where $n_{l m}$ is the number of meanings for which $l$ and $m$ were classified as cognate and $n_{l m}^{0}$ is the number of meanings for which $l$ and $m$ were not classified as cognate (Ginsburgh et al. 2005). Table A.4 in the Appendix summarizes the distance measures.

Validation fee - corresponds to the fee a patent holder has to pay to validate a granted patent in a member state of the EPC. Information on validation fees was extracted from the Official Journal and the National Law Relating to the EPC. ${ }^{23}$ The validation fee may comprise a fixed component and a variable (i.e. a page-based) component. However, most of the countries only charge a fixed fee. Some countries do not charge validation fees at all (Belgium, Switzerland, Luxembourg, Monaco, UK). For the countries which charge a page-based fee (Austria, Finland, Sweden, Denmark, and Spain) the average number of pages per patent, provided by the EPO, was used to compute the average total validation fees. ${ }^{24}$ Overall, the validation fees were calculated according to formula (2):

$$
F_{B}^{V}=F_{B}^{F}+F_{B}^{P} \cdot \bar{S}
$$

where $F_{B}^{V}$ denotes the validation fee for destination country $\mathrm{B}$ and $F_{B}^{F}$ the fixed validation fee for country B, $F_{B}^{P}$ refers to a the page-based fee if charged by country B, otherwise $F_{B}^{P}$ is zero. $\bar{S}$ denotes the average number of pages per patent specification.

Renewal fees - These fees have also been referred to as maintenance costs, i.e., costs to keep a patent valid for an additional year. With few exceptions, renewal fees increase with the year

Cf. http://www.epo.org/patents/law/legal-texts/national-law-epc.html (accessed on August 29, 2007).

24 Cf. table A. in the Appendix for a summary of the validation fees charged by different EPC member states. 
of renewal, but display considerable variation across countries. Renewal fees for the different years were again extracted from the "Official Journal and the National Law Relating to the $E P C^{\prime}$. Since we assume that the fees that have to be paid during the first years after grant matter most for the decision to validate a patent in a particular country, cumulative renewal fees for the years 4 to 6 from the date of filing of the application at the EPO are included in the regression. According to Harhoff and Wagner (2006) the average grant lag at the EPO is of about 4 years; and some recent data suggests a slightly longer lag (cf. van Zeebroeck, 2007b). Harhoff et al. (2007) show that a majority of patents is granted by the EPO at age 4 to 6. During this three years period, $66.5 \%$ of all the patents belonging to a given cohort are granted

Technical areas - Patent applications are classified according to 14 technical areas, known as "Joint Clusters" (JCs), used by the EPO since 2004 to assign patent applications to examiners. ${ }^{25}$ As there is some factual and empirical evidence (van Pottelsberghe and van Zeebroeck, 2008) showing that some technologies are traditionally subject to a large geographical scope of protection (i.e., biotechnology and organic chemistry), whereas others are validated in a very limited number of countries, the assigned area of technology may well affect the observed geographical scope of protection within the EPC.

Technology position of validation vs. applicant country - To control for the relative technology attractiveness of the validation country, we include a variable that accounts for the technology position of the validation country (B) compared to that of the applicant country (A) by dividing the number of patents in technology $i$ of the validation country (B) by the number of patents in technology $i$ of the applicant country (A) for five years before the grant of the patents, i.e. for the years 1998 to 2002.

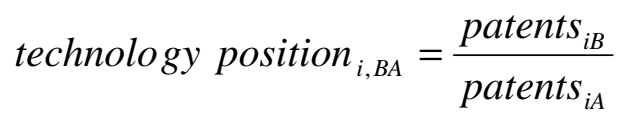

where $i=1, \ldots, 30$ refers to the technical area of the validated patent based on the OECD classification (OECD 1994). We expect that this measure will be positively associated with validation decisions, since a large production of patents in a particular technology in a potential target country is likely to indicate a large market for that technology in that country. For example, interviews with patent attorneys suggest that almost all patents on automotive technology target Germany as designation because this country constitutes one of the largest

25 EPO Joint Clusters: Industrial Chemistry, Organic Chemistry, Polymers, Biotechnology, Telecommunications, Audio/Video/Media, Electronics, Electricity/Electrical Machines, Computers, Measuring Optics, Handling/Processing, Vehicles/General Technology, Civil Engineering/Thermodynamics, Human Necessities. See Archontopoulos et al. (2007) for additional information about the assignment of the IPC classes to the EPO joint clusters. 
markets for automotive product and process technology. That of course is driven by strong domestic demand for the product itself.

\section{Descriptive Statistics}

The sample consists of 53,904 patents granted by the EPO in 2003. In some of our descriptive statistics, we compare the validation targets of these patents to those of the 1995 grant cohort $(\mathrm{N}=40,924)$. Figure 1 illustrates the share of granted EP patents validated in different EPC member states. Whereas 75 to 95 percent of the granted patents are validated in Germany, France and the UK, only about 20 to $30 \%$ are validated in The Netherlands, Spain, Switzerland, Sweden, Austria and Belgium. Smaller countries seem to be the less attractive, like for example, Ireland, Monaco, Portugal, or Finland. But one has to take into account that, for our sample, these countries were the last to enter the EPC and that these countries have experienced a large increase in validations over the last years. ${ }^{26}$

[Please insert Figure 1 about here]

Whereas the early members seem to have become less attractive for validation over time, more recent member states have become more attractive. However, as the number of patents granted by the EPO has constantly increased over the past 20 years, all member states have undergone an increase in the absolute number of validations per country over time.

Figure 2 displays the mean number of validated countries per 'applicant country'. In 1995 the applicants validated their patents on average in five countries, which slightly decreased to 4.9 in 2003. It is worth noticing that large countries' validations, or validations of countries which are far away from Europe, are concentrated on a smaller number of EPC member states. This is especially the case for the U.S., Japan and Korea, which are at the lower end of the distribution. Furthermore, the validation behavior of the latter three countries remained almost stable over time. U.S. applicants validate their patents in 5 countries on average. Korean and Japanese applicants validate in an average of 4 and 3.5 countries, respectively. For these countries the high costs associated with translation and validation as well as a large domestic market may induce them to be more selective in their European geographical scope.

[Please insert Figure 2 about here]

26 Table A.1 in the Appendix gives an overview over the dates of entry of the different member states into the EPC. 
The validation behavior of applicants also appears to vary substantially across technical areas. Table 1 illustrates the share of patents granted in 2003 that were finally validated in different EPC member states, differentiated by EPO "joint clusters" (which delineate different technologies for examination purposes). Whereas all EPC member states are most attractive for "organic chemistry" and "biotechnology", with validation rates considerably above the average in almost all EPC member states, validation rates are rather low for "audio, video \& media" and "computers".

[Please insert Table 1 about here]

Table 2 summarizes descriptive statistics of the independent variables that are to be used for the multivariate analyses. First of all, variables characterizing the applicant and the validation countries will be included in the regression. Due to the fact that large non-European countries, e.g., the U.S. or Japan apply for EP patents but can, of course, not be validation targets, the average wealth and size of the application countries is much larger than that of the validated countries. The average GDP per capita [in $1000 €$ ] of the applicant countries amounts to 33.0; varying from 12.7 (Korea) to 48.8 (Norway). The validation countries have an average GDP per capita [in $1000 €$ ] of 34.2 with a minimum at 14.9 (Portugal) and a maximum at 64.54 (Luxembourg and Monaco).

[Please insert Table 2 about here]

The applicant countries have on average 127.5 mio. inhabitants, the validation countries exhibit an average of 19.2 mio. inhabitants. The mean physical distance between the capital cities of the applicant and the validation countries amounts to $4,173.2 \mathrm{~km}$. The minimum physical distance amounts to $136 \mathrm{~km}$ (Belgium - Luxembourg), and the maximum to 18,044.0 km (Australia - Portugal). The medium technology position of the validation vs. the application country amounts to 0.7 , varying between 0 (e.g., A: Japan - B: Cyprus in organic chemistry) and 2,236 (A: Ireland - B: Germany in mechanical elements). Regarding the duration of membership, Belgium, Germany, France, Luxembourg, The Netherlands, Switzerland, and the UK entered into the EPC 25 years earlier (as of 2003), whereas the latest entrant, Cyprus, had only been a member of the EPC for 5 years (as of 2003). The average number of years of membership was 18.8 in 2003. The patents in the sample received on average 0.8 citations (within 3 years after publication of the search report). The number of 3 years citations varies between 0 and 107. On average 252.1 patents were granted to the applicants within 5 years before the grant of the patent in the sample. The size of the 5-year 
patent portfolio varies between 0 and 2,897. The patents in the sample comprise on average 12.6 claims at the time of grant, varying between 1 and 247.

The second group of variables provides information about the fees and costs that have to be paid to validate an EPO-granted patent in selected EPC member states and to keep the patent in force for the years 4 to 6 from the application date at the EPO. A number of dummy variables will be included in the regression to control for the translation costs arising at the time of validation. A translation was required for $74 \%$ of the total number of observed validations. Translations into Nordic languages and Greek are most expensive. Translations into Dutch, Portuguese, and Spanish are assumed to be less expensive. German, English, and French are the least expensive languages. Out of the observed validations, $27 \%$ concerned an expensive language, $19 \%$ a less expensive language, and $28 \%$ the group of least expensive languages. The Dyen language distance measure exhibits an average language distance of 0.46 varying between 0 (filing language equals language of the validation country) and 1 (distance between filing language and Finish).

Furthermore, Table 2 contains information about validation fees and renewal fees for the years 4 to 6 after application at the EPO. The average validation fee amounts to EUR 143.3, varying between EUR 0 (Switzerland, Monaco, Belgium, Luxembourg, and UK) and EUR 596 (Austria). The cumulative early renewal fees for patents granted in 2003 amount to EUR 280 on average and vary between EUR 143 (Luxembourg) and EUR 540 (Switzerland). Figure 3 displays renewal and validation fees for patents granted in 2003 categorized by translation cost groups. It clearly appears that validating and keeping a patent in force for the years 4 to 6 is more expensive in the Nordic countries, especially due to the high translation costs but also in Austria due to a high page-based validation fee (Austria charges a page based fee of $25 €$ per page in excess of five pages).

[Please insert Figure 3 about here]

\section{Empirical Implementation and Results}

\subsection{Econometric Model}

Since the dependent variable, i.e., the decision to validate a granted patent in a particular member state of the EPC is a binary response variable, a probit model is used for the 
quantitative analysis. The probability of observing a validation of a patent from country $\mathrm{A}$ in target country B is a function of a number of independent variables: ${ }^{27}$

$$
\begin{gathered}
\operatorname{Pr}(\text { Validation })=\Phi\left(\beta_{0}+\beta_{1} \ln Y_{A}+\beta_{2} \ln Y_{B}+\beta_{3} \ln N_{A}+\beta_{4} \ln N_{B}\right. \\
\left.+\beta_{5} \ln D_{A B}+\beta_{6} \ln F_{B}+\sum_{i} \beta_{7 i} \text { control }_{i}\right)
\end{gathered}
$$

where

$\mathrm{Y}_{\mathrm{A}}, \mathrm{Y}_{\mathrm{B}}=$ GDP per capita of the applicant and the validation countries

$\mathrm{N}_{\mathrm{A}}, \mathrm{N}_{\mathrm{B}}=$ total population of the applicant and the validation countries

$\mathrm{D}_{\mathrm{AB}}=$ physical distance between country $\mathrm{A}$ and country $\mathrm{B}$

$\mathrm{F}_{\mathrm{B}}=$ fees (validation or renewal) and translation requirements in country $\mathrm{B}$

control $_{\mathrm{i}}=$ control variables, e.g., region of the applicant, or joint technological clusters.

We assume that the error terms are independent across different groups of EPO-granted patents, but we allow for correlation within groups of different national patents originating from the same EPO grant. In order to accommodate the correlation, a cluster regression has been used. The cluster estimator leads to the same coefficients as a probit model without clustering of error terms, but it adjusts the variance-covariance matrix to account for observations for the same patent family to be correlated (Wooldridge 2002).

\subsection{Multivariate Results}

The parameters estimated with the probit regressions are displayed in Table 3. Model 3 shows that the wealth of the applicant country and the validation country have a significant impact on the probability of observing a validation. In particular, an increase in the GDP per capita of the applicant country (A) by one logarithmic unit leads to an increase of the probability to observe a validation of $7.6 \%$. An increase in the GDP per capita of the target country (B) by one unit raises the probability of observing a validation by $25.4 \%$. Both estimators are significant at the $1 \%$ level.

The size of the applicant and of the validation countries - as measured by the number of inhabitants - also has a positive impact on the probability of a validation. The estimated parameters suggest that an increase in the population of the applicant country A by one unit increases the probability to observe a validation by $2.3 \%$. An increase of the population variable of the validation country by one unit increases the probability of a validation by 13.5\%. Overall, the results in Table 3 show that the wealth and size of the validation countries generally have a higher effect than the same characteristics of the applicant countries.

27 A Wald-test was employed to test if a log linear or a linear specification was more appropriate. The results, which are available on request, clearly showed that the logarithmic specification was superior. 
The parameter associated with the age of EPC membership is negative and significant: the longer the EPC experience of a country, the lower the likelihood of a validation in that country. As expected, the technology position of validation countries in relation to that of the application countries has a positive and significant effect on the validation behavior of the applicant country. The number of claims also shows a positive and significant parameter: larger patents are filed in more countries ${ }^{28}$. A possible explanation is that patent applicants and attorneys devote more efforts on promising filings, and that the number of claims may, therefore, be reflective of the patent's importance.

The variable capturing the physical distance between the applicant and the validation countries has a negative and significant impact on the probability of a validation. The effect becomes insignificant after including translation cost dummies in the regression (which actually correlates with the geographical distance).

Model 3 includes the dummy variables indicating whether the costs for a translation are high, medium or low, or whether no translation was needed (reference group). The estimated parameters show that the impact of translations is negative compared to the reference group (no translation needed). In particular, when the translation costs are low, the validation probability decreases by $15 \%$. Medium translation costs decrease the probability of a validation by $24 \%$ and high translation costs by $21 \%$ (each compared to the reference group). Model 3 also shows the role of the geographical origin of the applicants. The probability of a validation is the lowest for the applicants originating from Japan and other non-European countries, and is the highest for applicants based in Europe. These results are again in line with the results shown in Figure 2 and with the findings of Guellec and van Pottelsberghe (2001) that large countries are less dependent on internationalization, since they already profit from large domestic markets.

Model 3 further contains variables measuring the value of the applications (forward patent citations) and the portfolio size of the applicant, as proxied with the number of patents granted to the applicants within 5 years before the grant of the underlying patents. Validations are more likely to occur for more valuable patent applications. In particular, a $1 \%$ increase in the value of a patent, i.e. a higher number of 3-years citations, increases the probability of a validation by $3 \%$. However, a $1 \%$ larger 5 -year patent portfolio of the applicants decreases the likelihood of a validation by $1.2 \%$. In other words, patents of larger firms or of firms that hold more patents are characterized by a more focused geographical scope of protection. The firms with a larger patent portfolio are characterized by a more selective market coverage.

\footnotetext{
${ }^{28}$ Van Zeebroeck and van Pottelsberghe (2008) show that the number of claims included in a patent correlates with many patent value indicators, including family size.
} 
[Please insert Table 3 about here]

Model 3 also measures the impact of validation fees and renewal fees on the validation behaviour of applicants. ${ }^{29}$ Renewal fees reduce the probability of observing a validation in a country. A $1 \%$ increase in the renewal fees would lead to a reduction in the probability of validation of about $12.6 \%$. An increase in the validation fees by $1 \%$ leads to a decrease in the validation probability of $5.3 \%$. Finally, it should be mentioned that the renewal fees have one of the highest $\mathrm{z}$-statistics, indicating a high precision of the estimates.

Model 4 includes the Dyen language distance measure, which forms an alternative and potentially more accurate proxy for translation costs. The results reveal that an increase of the Dyen language distance by $1 \%$ decreases the probability of a validation by $15.9 \%$. Model 4 also includes an interaction term "Dyen language distance * no. of claims at grant" to account for the voluminosity of the validated patents. In particular, the number of pages of a patent, which is highly correlated with the number of claims also affects translation costs. The effect of language distances on the validation behaviour is still negative and significant, and the number of claims has a positive impact. The interaction term is negative and significant which suggest that larger patents are less likely to be validated in countries with high translation costs.

EPO industry clusters dummies were used in all models as control variables. A Wald test conducted for each model reveals that the technical areas have a significant impact on the validation behavior of applicants. Overall, results are consistent with the findings displayed in Table 1, i.e. organic chemistry and biotechnology exhibit the largest impact on the probability to observe a validation (the parameters associated with industry clusters, estimated in Model 5, are shown in Table A.5 in the Appendix). These findings are consistent with the scope-year index put forward in van Pottelsberghe and van Zeebroeck (2008): patents in biotech and organic chemistry are validated in more countries and enforced longer than the patents filed in other technologies.

29 As a robustness check, we compared the determinants of validations over two grant years (2003 and 1995). To make a comparison of the two grant years reasonable, the two samples were built symmetrically with respect to potential validation countries. In particular, later entrants into the EPC (i.e. FI and CY) were excluded from the 2003 sample. Results are consistent with respect to the geographical context, languages, costs and fees. The only differences are that the wealth of the applicant country has a significantly negative effect on validations for the grant year 1995, whereas the effect is positive in 2003. A possible explanation of this difference may be that in recent years small applicant countries with a relatively low GDP per capita (e.g., ES, BE, and AT) validated more countries per granted EP patent (see Figure 2). Consistently, the distance between the capital cities of the applicant and the validation country has a negative impact. The coefficient decreases slightly from 1995 to 2003. Possibly, distances become less important over time, e.g., due to the internet and advancement of communication technologies. The complete results are available upon request. 
Overall, the results support hypotheses H.1a and H.1b as well as H.2a and H.2b. The size and the wealth of applicant and of the validation countries positively affect the propensity of applicants to validate patents abroad. Hypotheses H.3a, H.3b and H.3c are also confirmed by our estimates: transaction costs (i.e. validation costs, renewal fees and translation costs) have a strong and statistically significant influence on firms' decision to validate a patent abroad.

\subsection{Policy Simulation of the Impact of the "London Protocol"}

The London Protocol (or London Agreement) makes use of Article 65 EPC which foresees an option to reduce costs relating to the translation requirements of European patents. The agreement was concluded at the Intergovernmental Conference in London on October $17^{\text {th }}$ $2000 .^{30}$ The cost-reducing effect comes about as the EPC contracting states which have ratified or acceded to the Agreement waive, entirely or largely, the requirement for translations of European patents. Under Article 1(1), (2) and (3) of the London Agreement, all states which have an official language in common with one of the three official languages of the EPO shall drop the translation requirements provided for in Article 65(1) EPC, except for the claims section. Those states which do not have an official language in common with one of the EPO's official languages also drop the translation requirement of the description part of the patent, but require a translation of the claims into one of their official languages. On May $1^{\text {st }}, 2008$, the London Protocol came into force in 14 EPC member states ${ }^{31}$. In November 2008 the London Protocol was signed (but is still to be ratified) in Belgium. Ten of these 15 member states are represented in our sample: Switzerland, Germany, Denmark, France, the UK, Luxembourg, Monaco, The Netherlands, Sweden, and Belgium.

We use the parameters estimated in Model 5 (containing the translation dummies and the Dyen language distance measure, each interacted with the number of claims at grant to account for the voluminosity of the patents) to estimate the impact of the London Protocol on validation behavior. To obtain our simulation results, we first simulate the costs of translation as foreseen by the London Protocol by switching the respective translation dummies and the Dyen measure to zero. We then predict the likelihood of validation using the estimated coefficients of Model 5. The results of these simulations are tabulated in Table 4.

When interpreting the results, one has to take into account that our estimates are likely to yield upper bounds of the actual effect. This is the case for two reasons: first, claims will still have to be translated into the respective language, and second, our language variables may

30 See Official Journal EPO 2001, 549ff. http://www.european-patent-office.org/epo/pubs/oj001/12 01/ 12_5491.pdf, accessed on December 28, 2008.

31 As of May $1^{\text {st }}, 2008$ the London Protocol was enforced in Croatia, Denmark, France, Germany, Iceland, Latvia, Liechtenstein, Luxembourg, Monaco, The Netherlands, Slovenia, Sweden, Switzerland, and the UK (see http://www.epo.org/patents/law/legal-texts/london-agreement/status.html, accessed on June 22, 2008). 
capture to some degree variation that is related to missing variables. We have tried to minimize the second effect by taking into account a number of variables which affect the cost of doing business in the target country, but these controls may not be perfect. Despite these caveats, our results should be of interest to policy-makers. First, results in Table 4 correspond to the legal situation after May $1^{\text {st }}, 2008$, i.e., after the London Protocol came into force in the ten EPC member states mentioned above (columns 3 and 6 of Table 4). Afterwards, we show changes in the number of validations if the London Protocol were ratified by all EPC member states represented in our sample (columns 4 and 7 of Table 4).

[Please insert Table 4 about here]

Table 4 suggests that those countries that put the London Protocol into national law after May $1^{\text {st }}, 2008$ will experience a substantial increase in the probability of validation. The largest absolute increase can be expected for the Netherlands $(19,162)$ and Sweden $(13,840)$. Overall, we predict that, for those countries that ratified the London Protocol, national patent validations may increase by as much as $29 \%$ (75,053 additional validated patents) due to the cost reductions resulting from the reduction of translation requirements. ${ }^{32}$

Assuming that all countries signed the London Protocol leads to a further increase in the predicted probability of validation for all countries (column 4) except for Monaco and Luxembourg. The highest increase in the number of national patents can be observed in Spain $(21,292)$ and the Netherlands $(19,162)$. Overall, we estimate that the absolute number of additional validated patents may amount to as many as 153,832 , which would be equivalent to a relative increase of $59.3 \%$. Of course, these estimates can merely give a rough indication and represent upper-bound figures of additional validations. On the other hand, they do not take into account the fact that the overall costs of patenting will decrease as well due to the London Protocol which may induce an increase in patent filings.

\section{Concluding Remarks}

The European patent system provides an interesting field for the empirical analysis of patent systems. The variation in our data allows us to investigate to what extent patent applicants are influenced by both the fees and translation costs, as well as by physical distances and market attractiveness (represented by its size, its wealth or the technical position of the validation country relative to the applicant country). Our paper analyzes a particularly clear decision-

\footnotetext{
${ }^{32}$ Although Monaco and Luxembourg also ratified the London Protocol, Table 4 (column 6) does not show a change in the number of national patent validations for these countries. This is not surprising, since these two countries had not required translations for validations even before the London Protocol came into force.
} 
making situation where fees and translation costs are the only remaining expenses that separate applicants from patent protection. The empirical results are applied to assess the impact of an important patent policy reform, the London Protocol, which has had a major impact on the translation costs of European patents.

The empirical analysis essentially aimed at testing the role of languages (i.e., translation costs) and the role of fees for validation and early renewal. A patent-level probit model was used estimate the incidence of patent validation of an EPO-granted patent in a given EPC country. Economic variables such as the size and the wealth of the countries of origin (the country of residence of the applicant) and of the countries of destination where the patent is validated are important determinants of the validation probability. In general, the characteristics of the validation country (where the patent is validated and enforced) have a much stronger impact on validations than the characteristics of the origin country.

Technological specificities and geographical distance were included as additional explanatory variables. These characteristics are important factors affecting the probability of validation of a patent in a given country. The world may have become more globalized, but it certainly has not become "completely flat". Physical distance still matters, and so does the distance in culture and languages. The empirical analysis also shows that translation costs have a negative impact on validations. Furthermore, our results show that early renewal fees and validation fees substantially reduce the likelihood of validating a patent in a given country.

The unique and rich dataset which exploits the institutional detail of the European patent system also permits us to make predictions regarding the number of additional validations that EPC member states may expect in the future. A simulation of the validation decision under London Protocol translation regulation shows that the countries that ratified the London Protocol face an increasing probability of validations. In particular, we predict that the number of additional validated patents will increase between 29\%. Should all EPC member state ratify the London Protocol, the increase could reach $59.3 \%$ of the validations performed in 2003. Our estimates only capture the impact of the marginal cost of patenting on validation. It is highly likely that the cost reduction coming with the implementation of the London Protocol will affect the overall number of filings at the EPO, and hence the number of grants which are then subject to the validation decision studied here. ${ }^{33}$ We plan to investigate the

\footnotetext{
${ }^{33}$ According to the initial simulations performed by van Pottelsberghe and Mejer (2008) the total number of patent applications could increase by nearly $30 \%$ thanks to the reduction in translation costs. However the current economic crisis will evidently overshadow the cost effect and lead to a fall in the number of patent applications.
} 
overall impact of current reforms and reform proposals in future work building on the econometric results described in this paper. 


\section{References}

Abrams, R.K. (1980). International Trade Flows under Flexible Exchange Rates, Federal Reserve Bank of Kansas City, Economic Review 65(3): 3-10.

Archontopoulos, E. / Guellec, D. /. Stevnsborg, N. / van Pottelsberghe de la Potterie, B./ van Zeebroeck, N. (2007). When Small is Beautiful: Measuring the Evolution and Consequences of the Voluminosity of Patent Applications at the EPO, Information Economics and Policy 19(2): 103-132.

Arundel, A. (2001). The Relative Effectiveness of Patents and Secrecy for Appropriation, Research Policy 30: 611-624.

Blind, K. / Edler, J. / Frietsch, R. / Schmoch, U. (2006). Motives to Patent: Empirical Evidence from Germany, Research Policy 35: 655-672.

Bosworth, D.L. (1984). Foreign Patent Flows to and from the United Kingdom, Research Policy 13: 115-124.

Cohen, W. / Nelson, R.R. / Walsh, J. (2000). Protecting Their Intellectual Assets: Appropriability Conditions And Why U.S. Manufacturing Firms Patent (Or Not), NBER Working Paper No. 7552, Cambridge, MA.

Deng, Yi (2007). Private Value of European Patents, European Economic Review 51: 17851812.

de Rassenfosse, G. / van Pottelsberghe de la Potterie, B. (2007). Per un Pugno di Dollari: A First Look at the Price Elasticity of Patents, Oxford Review of Economic Policy 23(4): 1-17.

de Rassenfosse G. / van Pottelsberghe de la Potterie, B. (2008). On the Price Elasticity of Demand for Patents, ECARES Working Paper, 2008-031.

Dyen, I. / Kruskal, J.B. / Black, p. (1992). An Indo-European Classification: A Lexicostatistical Experiment, Transactions of the American Philosophical Society New Series 82(5), Philadelphia: American Philosophical Society: iii-132.

Eaton, J. / Kortum, S. (1996). Trade in Ideas Patenting and Productivity in the OECD, Journal of International Economics 40(3-4): 251-278.

Eaton, J. / Kortum, S. / Lerner, J. (2004). International Patenting and the European Patent Office: A Quantitative Assessment, in Patents, Innovation and Economic Performance: OECD Conference Proceedings, Paris and Washington, D.C.: Organisation for Economic Co-operation and Development, 2004: 27-52.

Friedman, T.L. (2006). The World is Flat - The Globalized World in the Twenty-First Century, Penguin Books.

Gambardella, A. / Harhoff, D. / Verspagen, B. (2008). The Value of European Patents, European Management Review 5: 69-84.

Geraci, V.J. / Prewo, W. (1977). Bilateral Trade Flows and Transport Costs, The Review of Economics and Statistics 64: 67-74. 
Ginsburgh, V. / Ortuño-Ortín, I. / Weber, S. (2005). Disenfranchisement in Linguistically Diverse Societies - The Case of the European Union, CEPR Discussion Paper No. 4875 .

Guellec, D. / van Pottelsberghe de la Potterie B. (2001). The Internationalisation of Technology Analyzed with Patent Data, Research Policy 30(8): 1253-1266.

Guellec, D. I van Pottelsberghe de la Potterie B. (2007). The Economics of the European Patent System, Oxford: Oxford University Press.

Harhoff, D. (2006). Patent Quantity and Quality: Trends and Policy Implications, in: Kahin, B. / Foray, D. (Eds.): Advancing Knowledge and the Knowledge Economy, Cambridge, Mass: MIT Press.

Harhoff, D. / Hoisl, K. / Reichl, B. / van Pottelsberghe de la Potterie, B. (2007). Patent Validation at the Country Level - The Role of Fees and Translation Costs, CEPR Discussion Paper, DP 6565.

Harhoff, D. / Wagner, S. (2006). Modelling the Duration of Patent Examination at the European Patent Office, CEPR Discussion Paper, DP 5283.

OECD 1994. Using Patent Data as Science and Technological Indicators - Patent Manual 1994, Paris.

Pakes A / Schankerman, M. (1984). The Rate of Obsolescence of Patents, Research Gestation Lags and the Private Rate of Return to Research Resources, in: Griliches Z. (Ed.): R\&D, patents and productivity, Chicago: University of Chicago.

Peeters, C. / van Pottelsberghe de la Potterie, B. (2006). Innovation Strategy and the Patenting Performances of Large Firms, Journal of Evolutionary Economics, 16(1-2), 109-135.

Porter, M.E. / Stern, S. (2000). Measuring the "Ideas" Production Function: Evidence from International Patent Output, NBER Working Paper No. 7891, Cambridge, MA.

Putnam, J. (1996) The Value of International Patent Rights. PhD Thesis, Yale University.

Slama, J. (1981). Analysis by Means of a Gravitation Model of International Flows of Patent Applications in the Period 1967-1978, World Patent Information 3(1): 2-8.

Schankerman, M. / Pakes A. (1986). Estimates of the Value of Patent Rights in European Countries During the Post 1950 Period, Economic Journal 96(384): 1052-1076.

Stevnsborg N. / van Pottelsberghe de la Potterie, B. (2007). Patenting Procedures and Filing Strategies, in Guellec, D. / van Pottelsberghe de la Potterie, B. (Ed.): The Economics of the European Patent System, Oxford: Oxford University Press, Oxford, Chapter 6, pp. 155-183.

Tinbergen, J. (1962). Shaping the World Economy: Suggestions for an International Economic Policy, New York: The Twentieth Century Fund.

van Pottelsberghe de la Potterie, B. / François, D. (2009). The Cost Factor in Patent Systems, Journal of Industry, Competition and Trade, forthcoming. 
van Pottelsberghe de la Potterie B. / M. Mejer (2008). The London Agreement and the cost of patenting in Europe, Bruegel Working Paper, 2008/05, and ECARES Working Paper, 2008-032.

van Pottelsberghe de la Potterie, B. / van Zeebroeck, N. (2008). A Brief History of Space and Time: The Scope-Year Index as a Patent Value Indicator Based on Families and Renewals, Scientometrics, 75(2), 319-338.

van Zeebroeck, N. (2007a). The puzzle of patent value indicators, Working Papers CEB 07023.

van Zeebroeck, N. (2007b). Patents only live twice: a patent survival analysis in Europe, Working Papers CEB 07-028.

van Zeebroeck, N. / van Pottelsberghe de la Potterie, B. / Guellec, D. (2006). Claiming More: The Increased Voluminosity of Patent Applications and its Determinants, CEPR Discussion Paper, 5971..

von Graevenitz / Wagner, S. / Harhoff, D. (2008). Patent Thickets - Do they exist, do they matter?, unpublished manuscript, University of Munich.

Wooldridge, J.M. (2002). Introductory Econometrics - A Modern Approach, South Western / Thomson Learning. 
Figure 1: Share of granted EP patents validated in EPC contracting states (by grant year), $\mathrm{N}_{1995}=40,924, \mathrm{~N}_{2003}=53,904^{34}$

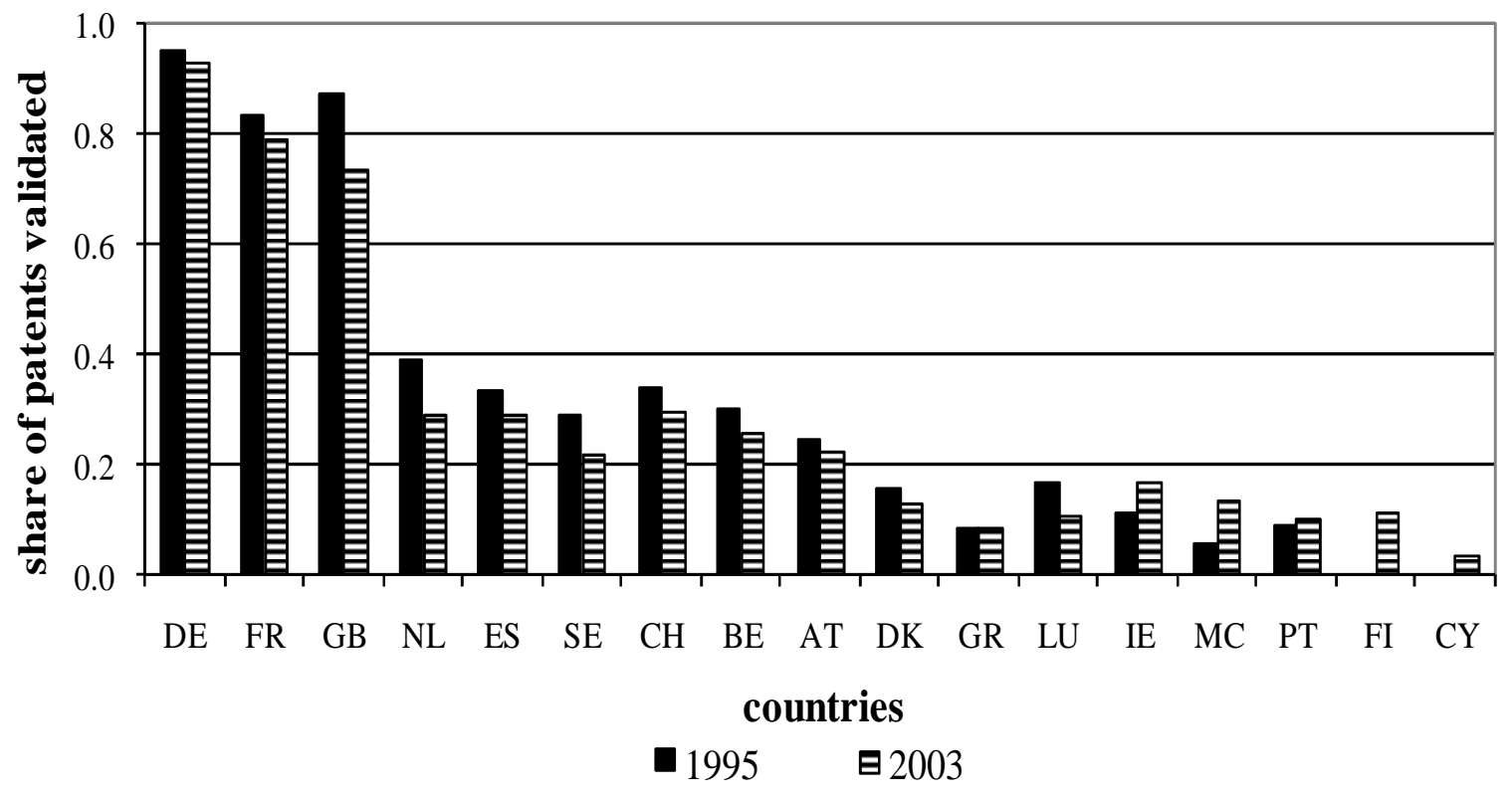

Figure 2: $\quad$ Average number of validations per granted EP patent (by grant year and by applicant country), $\mathrm{N}_{1995}=40,924 ; \mathrm{N}_{2003}=53,904$

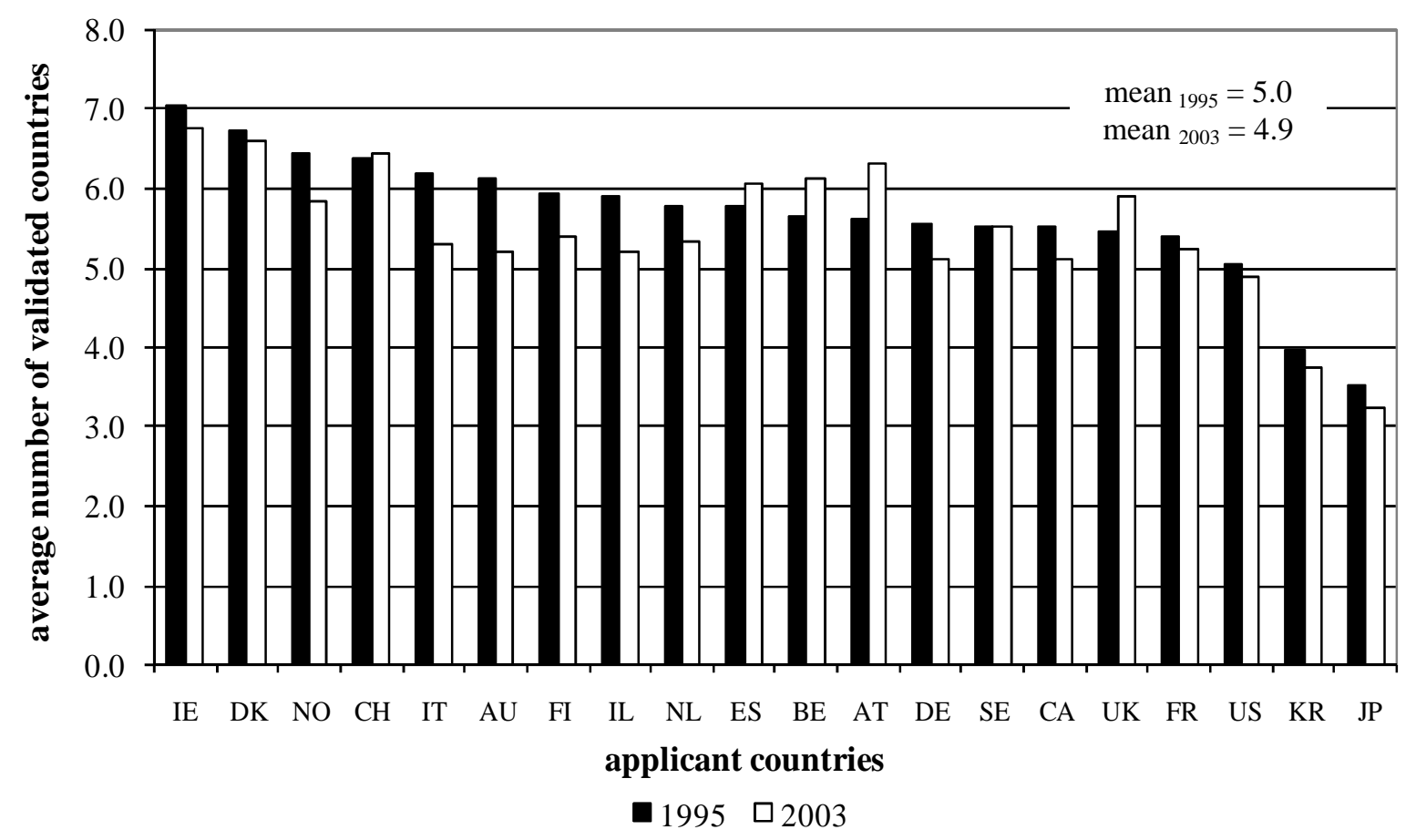

34 The abbreviations of the countries are defined in Table A.3 in the Appendix. 
Figure 3: Average costs (validation fees and renewal fees) to be paid to validate a patent in a particular member state of the EPC and to keep it in force for the years 4 to 6 (patents granted in 2003).

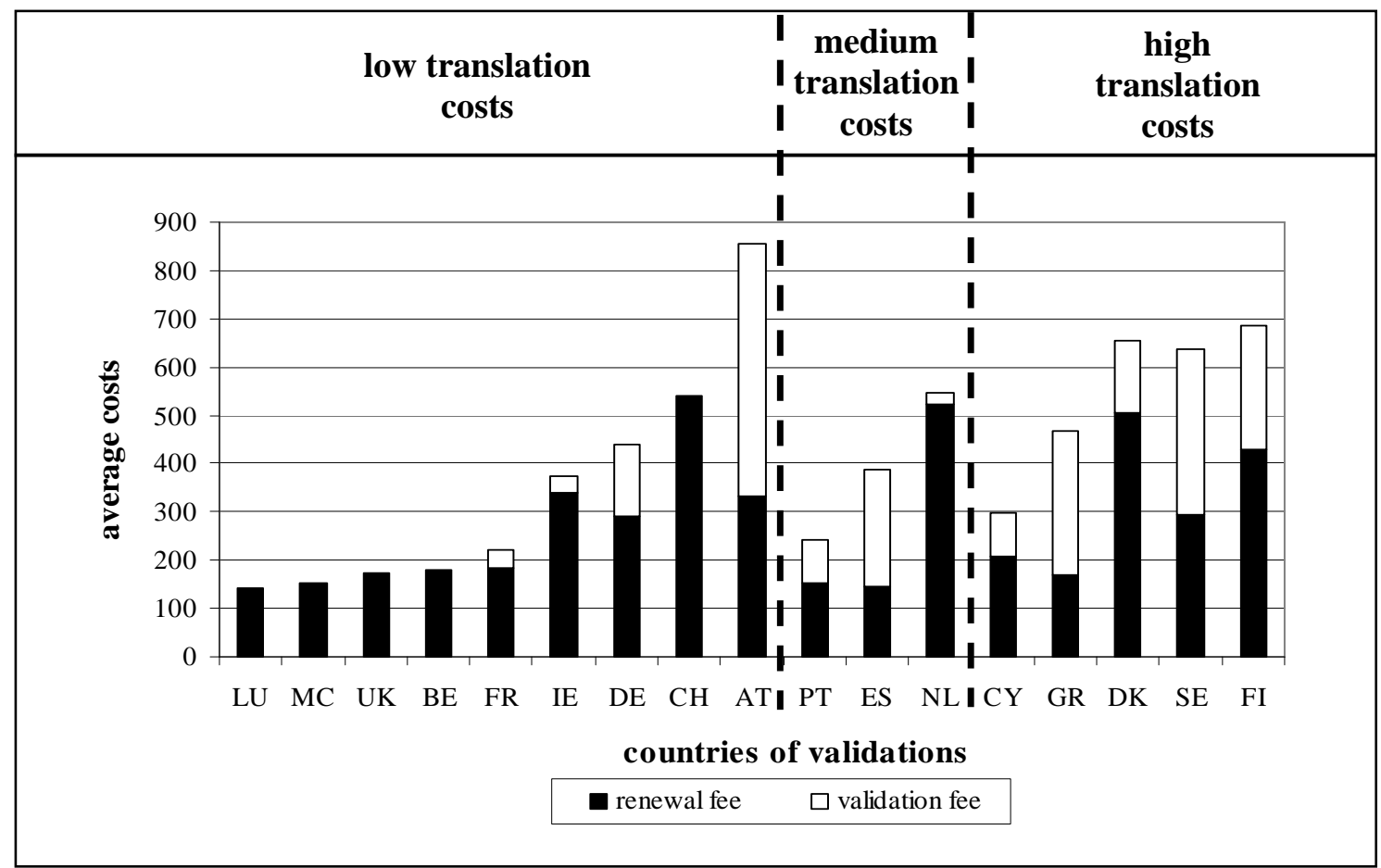


Table 1: $\quad$ Share of granted EP patents validated in each EPC contracting states (by joint technical clusters), grant year $=2003, \mathrm{~N}_{2003}=53,904$

\begin{tabular}{|l|c|c|c|c|c|c|c|c|c|c|c|c|c|c|c|c|c|}
\hline \hline & DE & FR & GB & NL & SE & CH & BE & AT & LU & ES & DK & GR & IE & MC & PT & FI & CY \\
\hline Industrial Chemistry & 0.93 & 0.79 & 0.74 & 0.36 & 0.24 & 0.30 & 0.33 & 0.25 & 0.11 & 0.30 & 0.13 & 0.07 & 0.16 & 0.14 & 0.10 & 0.13 & 0.02 \\
\hline Organic Chemistry & 0.95 & 0.89 & 0.81 & 0.52 & 0.35 & 0.53 & 0.52 & 0.39 & 0.25 & 0.54 & 0.32 & 0.27 & 0.40 & 0.27 & 0.28 & 0.24 & 0.10 \\
\hline Polymers & 0.96 & 0.83 & 0.78 & 0.38 & 0.20 & 0.23 & 0.32 & 0.18 & 0.08 & 0.32 & 0.10 & 0.05 & 0.14 & 0.11 & 0.08 & 0.10 & 0.01 \\
\hline Biotechnology & 0.95 & 0.89 & 0.86 & 0.50 & 0.42 & 0.60 & 0.51 & 0.44 & 0.33 & 0.50 & 0.38 & 0.30 & 0.47 & 0.32 & 0.31 & 0.26 & 0.11 \\
\hline Telecommunications & 0.91 & 0.78 & 0.79 & 0.14 & 0.17 & 0.12 & 0.09 & 0.08 & 0.04 & 0.14 & 0.05 & 0.02 & 0.08 & 0.08 & 0.02 & 0.07 & 0.00 \\
\hline Audio/Video/Media & 0.92 & 0.79 & 0.85 & 0.18 & 0.09 & 0.11 & 0.08 & 0.06 & 0.04 & 0.13 & 0.05 & 0.02 & 0.08 & 0.06 & 0.02 & 0.05 & 0.00 \\
\hline Electronics & 0.90 & 0.77 & 0.78 & 0.18 & 0.13 & 0.16 & 0.11 & 0.11 & 0.04 & 0.14 & 0.04 & 0.03 & 0.09 & 0.07 & 0.03 & 0.06 & 0.01 \\
\hline $\begin{array}{l}\text { Electricity \& } \\
\text { Electrical Machnies }\end{array}$ & 0.93 & 0.76 & 0.70 & 0.20 & 0.14 & 0.19 & 0.14 & 0.12 & 0.05 & 0.15 & 0.04 & 0.02 & 0.08 & 0.08 & 0.04 & 0.06 & 0.00 \\
\hline Computers & 0.90 & 0.77 & 0.85 & 0.15 & 0.10 & 0.15 & 0.11 & 0.10 & 0.05 & 0.15 & 0.05 & 0.03 & 0.13 & 0.09 & 0.03 & 0.04 & 0.01 \\
\hline Measuring Optics & 0.92 & 0.77 & 0.77 & 0.20 & 0.14 & 0.25 & 0.14 & 0.13 & 0.06 & 0.16 & 0.07 & 0.04 & 0.11 & 0.09 & 0.04 & 0.05 & 0.01 \\
\hline $\begin{array}{l}\text { Handling \& } \\
\text { Processing }\end{array}$ & 0.94 & 0.74 & 0.64 & 0.26 & 0.24 & 0.36 & 0.28 & 0.28 & 0.10 & 0.34 & 0.11 & 0.07 & 0.15 & 0.15 & 0.10 & 0.11 & 0.02 \\
\hline $\begin{array}{l}\text { Vehicles \& General } \\
\text { Technology }\end{array}$ & 0.93 & 0.77 & 0.65 & 0.16 & 0.21 & 0.19 & 0.15 & 0.15 & 0.05 & 0.27 & 0.07 & 0.04 & 0.07 & 0.08 & 0.05 & 0.05 & 0.01 \\
\hline $\begin{array}{l}\text { Civil Engineering / } \\
\text { Thermodynamics }\end{array}$ & 0.90 & 0.72 & 0.64 & 0.26 & 0.18 & 0.27 & 0.22 & 0.23 & 0.08 & 0.25 & 0.11 & 0.06 & 0.10 & 0.09 & 0.08 & 0.07 & 0.01 \\
\hline Human Necessities & 0.94 & 0.80 & 0.71 & 0.30 & 0.21 & 0.33 & 0.26 & 0.23 & 0.10 & 0.29 & 0.13 & 0.08 & 0.18 & 0.14 & 0.08 & 0.08 & 0.02 \\
\hline \hline
\end{tabular}

Table 2: $\quad$ Descriptive statistics $(\mathrm{N}=862,549$ country pairs $)$

\begin{tabular}{|l|r|r|r|r|}
\hline \hline Variable & \multicolumn{1}{|c|}{ Mean } & \multicolumn{1}{c|}{ Std.Dev. } & \multicolumn{1}{c|}{ Min } & \multicolumn{1}{c|}{ Max } \\
\hline GDP per capita: applicant country [1000 US\$] & 32.99 & 4.84 & 12.71 & 48.78 \\
\hline GDP per capita: validation country [1000 US\$] & 34.21 & 14.02 & 14.89 & 64.54 \\
\hline Population: applicant country [mio.] & 127.52 & 101.87 & 3.98 & 291.00 \\
\hline Population: validation country [mio.] & 19.21 & 23.65 & 0.03 & 82.52 \\
\hline Years membership EPC (validation country) & 18.78 & 7.00 & 5 & 25 \\
\hline Physical distance between capital cities [km] & 4173.17 & 3565.92 & 136 & 18044 \\
\hline Technology position applicant vs. validation country & 0.70 & 6.44 & 0 & 2236 \\
\hline Origin of the applicant (0/1) & 0.54 & & 0 & 1 \\
\hline Europe & 0.26 & & 0 & 1 \\
\hline US applicant & 0.17 & & 0 & 1 \\
\hline Japanese applicant & 0.03 & & 0 & 1 \\
\hline Other non-Europe & 12.57 & 9.07 & 1 & 247 \\
\hline No. of claims at grant & 0.84 & 1.69 & 0 & 107 \\
\hline Citations & 252.10 & 551.77 & 0 & 2897 \\
\hline Patent portfolio (5 years) & \multicolumn{5}{|l|}{} \\
\hline Translation costs (0/1) & 0.26 & & 0 & 1 \\
\hline Translation not required & 0.27 & & 0 & 1 \\
\hline High translation costs & 0.19 & & 0 & 1 \\
\hline Medium translation costs & 0.28 & & 0 & 1 \\
\hline Low translation costs & 0.46 & 0.33 & 0 & 1 \\
\hline Language distance matrix (Dyen) & 143.29 & 171.00 & 0 & 596.25 \\
\hline Validation fees [€] & 280.07 & 140.06 & 143 & 540 \\
\hline Renewal fees for years 4 to 6 [€]
\end{tabular}


Table 3: Multivariate analysis of patent validations for 2003 (marginal effects from robust probit regression, standard errors adjusted for intra-group correlation); $\mathrm{N}=862,549$

\begin{tabular}{|c|c|c|c|c|c|}
\hline \multirow[b]{2}{*}{ Dependent variable } & Model 1 & Model 2 & Model 3 & Model 4 & Model 5 \\
\hline & \multicolumn{5}{|c|}{ Validation $(0 / 1)$} \\
\hline \multicolumn{6}{|l|}{ Geographical context } \\
\hline $\begin{array}{l}\text { GDP per capita of applicant } \\
\text { country (log) }\end{array}$ & $\begin{array}{l}0.161 * * * \\
{[0.015]}\end{array}$ & $\begin{array}{l}0.138 * * * \\
{[0.015]}\end{array}$ & $\begin{array}{l}0.076^{* * *} \\
{[0.015]}\end{array}$ & $\begin{array}{l}0.099 * * * \\
{[0.015]}\end{array}$ & $\begin{array}{l}0.068 * * * \\
{[0.015]}\end{array}$ \\
\hline GDP per capita of validation & $0.266^{* * * *}$ & $0.450 * * *$ & $0.254 * * *$ & $0.373 * * *$ & $0.242 * * *$ \\
\hline country $(\log )$ & {$[0.002]$} & {$[0.003]$} & {$[0.003]$} & {$[0.003]$} & {$[0.003]$} \\
\hline Population of applicant country (log) & $0.037 * * *$ & $0.034 * * *$ & $0.023^{* * *}$ & $0.033 * * *$ & $0.022 * * *$ \\
\hline & {$[0.002]$} & {$[0.002]$} & {$[0.002]$} & {$[0.002]$} & {$[0.002]$} \\
\hline Population of validation country (log) & $0.116^{* * *}$ & $0.143 * * *$ & $0.135^{* * *}$ & $0.147 * * *$ & $0.135 * * *$ \\
\hline & {$[0.001]$} & {$[0.001]$} & {$[0.001]$} & [0.001] & {$[0.001]$} \\
\hline \multicolumn{6}{|l|}{ Costs of business in the target country } \\
\hline $\begin{array}{l}\text { Years membership EPC of the } \\
\text { validation country }(\log )\end{array}$ & $\begin{array}{l}0.041 * * * \\
{[0.001]}\end{array}$ & $\begin{array}{l}-0.033 * * * \\
{[0.001]}\end{array}$ & $\begin{array}{l}-0.007 * * * \\
{[0.001]}\end{array}$ & $\begin{array}{l}-0.056 * * * \\
{[0.002]}\end{array}$ & $\begin{array}{l}-0.022 * * * \\
{[0.002]}\end{array}$ \\
\hline Physical distance between capital & $-0.020 * * *$ & $-0.029 * * *$ & -0.0005 & $-0.012 * * *$ & -0.001 \\
\hline cities (log) & {$[0.002]$} & {$[0.002]$} & {$[0.002]$} & {$[0.002]$} & {$[0.002]$} \\
\hline Technology position of validation vs. & $0.151 * * *$ & $0.146^{* * *}$ & $0.112 * * *$ & $0.145^{* * *}$ & $0.111 * * *$ \\
\hline applicant country $(\log )$ & [0.003] & {$[0.003]$} & {$[0.003]$} & [0.003] & {$[0.003]$} \\
\hline USA $(0 / 1)$ & $-0.070 * * *$ & $-0.048 * * *$ & $-0.071 * * *$ & $-0.066 * * *$ & $-0.068 * * *$ \\
\hline Japan $(0 / 1)$ & $-0.094 * * *$ & $\begin{array}{l}{[0.000]} \\
-0.078 * * *\end{array}$ & $-0.125 * * *$ & $-0.106 * * *$ & $-0.123 * * *$ \\
\hline & {$[0.005]$} & {$[0.005]$} & {$[0.005]$} & {$[0.005]$} & {$[0.005]$} \\
\hline Other non-Europe $(0 / 1)$ & $-0.067 * * *$ & $-0.054 * * *$ & $-0.107 * * *$ & $-0.098 * * *$ & $-0.109 * * *$ \\
\hline & [0.009] & {$[0.009]$} & {$[0.008]$} & {$[0.008]$} & {$[0.008]$} \\
\hline \multicolumn{6}{|c|}{ Translation costs dummies - reference group: no translation needed } \\
\hline low translation costs $(0 / 1)$ & & & $\begin{array}{l}-0.151 * * * \\
{[0.001]}\end{array}$ & & $\begin{array}{l}-0.113 * * * \\
{[0.002]}\end{array}$ \\
\hline Medium translation costs $(0 / 1)$ & & & $-0.243^{* * *}$ & & $-0.223 * * *$ \\
\hline & & & {$[0.002]$} & & {$[0.002]$} \\
\hline High translation costs $(0 / 1)$ & & & $-0.221 * * *$ & & $-0.189 * * *$ \\
\hline & & & {$[0.002]$} & & {$[0.002]$} \\
\hline \multicolumn{6}{|l|}{ Translation costs - DYEN distance matrix } \\
\hline Language distance (DYEN matrix) & & & & $\begin{array}{l}-0.159 * * * \\
{[0.007]}\end{array}$ & $\begin{array}{l}-0.045 * * * \\
{[0.007]}\end{array}$ \\
\hline Language distance (DYEN matrix) & & & & $-0.015^{* * *}$ & $-0.015^{* * *}$ \\
\hline \multicolumn{6}{|l|}{ Other patent characteristics } \\
\hline Number of claims at grant $(\log )$ & $\begin{array}{l}0.015^{* * * *} \\
{[0.002]}\end{array}$ & $\begin{array}{l}0.016 * * * \\
{[0.002]}\end{array}$ & $\begin{array}{l}0.017 * * * \\
{[0.002]}\end{array}$ & $\begin{array}{l}0.023 * * * \\
{[0.002]}\end{array}$ & $\begin{array}{l}0.024 * * * \\
{[0.002]}\end{array}$ \\
\hline Citations $(\log )$ & $0.028 * * *$ & $0.029 * * *$ & $0.030 * * *$ & $0.030 * * *$ & $0.030 * * *$ \\
\hline & {$[0.002]$} & {$[0.002]$} & {$[0.002]$} & [0.002] & {$[0.002]$} \\
\hline Patent portfolio ( 5 years) & $-0.011 * * *$ & $-0.011 * * *$ & $-0.012 * * *$ & $-0.012 * * *$ & $-0.012 * * *$ \\
\hline$(5$ years $)(\log )$ & {$[0.000]$} & {$[0.000]$} & {$[0.000]$} & {$[0.000]$} & {$[0.000]$} \\
\hline \multicolumn{6}{|l|}{ Validation fees and renewal Fees } \\
\hline Validation fees (log) & & $\begin{array}{l}-0.014 * * * \\
{[0.000]}\end{array}$ & $\begin{array}{l}-0.053 * * * \\
{[0.001]}\end{array}$ & $\begin{array}{l}-0.023 * * * \\
{[0.000]}\end{array}$ & $\begin{array}{l}-0.052 * * * \\
{[0.001]}\end{array}$ \\
\hline Renewal fees for years 4 to $6(\log )$ & & $-0.187 * * *$ & $-0.126^{* * *}$ & $-0.191 * * *$ & $-0.137 * * *$ \\
\hline & & {$[0.001]$} & {$[0.001]$} & [0.001] & {$[0.002]$} \\
\hline \multicolumn{6}{|l|}{ Control variables } \\
\hline EPO Industry Clusters (Wald test); & $\operatorname{chi} 2(13)=$ & $\operatorname{chi} 2(13)=$ & $\operatorname{chi} 2(13)=$ & $\operatorname{chi} 2(13)=$ & $\operatorname{chi} 2(13)=$ \\
\hline Reference group: Vehicles/General & $5,729.37$ & $5,809.84$ & $5,900.49$ & $5,850.82$ & $5,910.11$ \\
\hline Technology $(0 / 1)$ & $\mathrm{p}=0.000$ & $\mathrm{p}=0.000$ & $\mathrm{p}=0.000$ & $\mathrm{p}=0.000$ & $\mathrm{p}=0.000$ \\
\hline Pseudo R2 & 0.231 & 0.254 & 0.274 & 0.262 & 0.274 \\
\hline log-likelihood & $-397,111.4$ & $-385,132.6$ & $-374,943.1$ & $-381,124.4$ & $-374,676.7$ \\
\hline
\end{tabular}

Robust standard errors in brackets / * significant at 10\%; ** significant at 5\%; *** significant at $1 \%$ 
Table 4: $\quad$ Simulation of Validation Decisions under London Protocol Translation Rules (based on Model 5)

\begin{tabular}{|c|c|c|c|c|c|c|}
\hline Country & $\begin{array}{l}\text { Share of } \\
\text { patents } \\
\text { validated } \\
\text { (before } \\
\text { London } \\
\text { Protocol) }\end{array}$ & $\begin{array}{c}\text { Predicted } \\
\text { probability of } \\
\text { validation under } \\
\text { London Protocol } \\
\text { (as of May } 1^{\text {st }} \text {, } \\
2008)\end{array}$ & $\begin{array}{l}\text { Predicted } \\
\text { probability of } \\
\text { validation } \\
\text { under London } \\
\text { Protocol } \\
\text { (all countries } \\
\text { signed) }\end{array}$ & $\begin{array}{c}\text { Actual } \\
\text { validations } \\
\text { in } 2003\end{array}$ & $\begin{array}{c}\text { Predicted } \\
\text { additional } \\
\text { validations } \\
\text { in } 2003 \\
\text { (London } \\
\text { Protocol as } \\
\text { of May } 1^{\text {st }} \text {, } \\
2008 \text { ) }\end{array}$ & $\begin{array}{c}\text { Predicted } \\
\text { additional } \\
\text { validations } \\
\text { in } 2003 \\
\text { (London } \\
\text { Protocol } \\
\text { signed by } \\
\text { all EPC } \\
\text { countries) }\end{array}$ \\
\hline Austria & 0.25 & 0.25 & 0.36 & 13,307 & 0 & 5,855 \\
\hline Belgium* & 0.29 & 0.46 & 0.46 & 15,436 & 9,049 & 9,049 \\
\hline Switzerland* & 0.27 & 0.36 & 0.36 & 14,372 & 4,791 & 4,791 \\
\hline Cyprus & 0.02 & 0.02 & 0.11 & 1,065 & 0 & 4,791 \\
\hline Germany ${ }^{*}$ & 0.76 & 0.87 & 0.87 & 40,454 & 5,855 & 5,855 \\
\hline Denmark ${ }^{*}$ & 0.16 & 0.39 & 0.39 & 8,517 & $12,24 \_3$ & 12,243 \\
\hline Spain & 0.30 & 0.30 & 0.70 & 15,969 & 0 & 21,292 \\
\hline Finland & 0.09 & 0.09 & 0.33 & 4,791 & 0 & 12,775 \\
\hline France & 0.77 & 0.90 & 0.90 & 40,986 & 6,920 & 6,920 \\
\hline $\mathrm{UK}^{*}$ & 0.71 & 0.77 & 0.77 & 37,793 & 3,194 & 3,194 \\
\hline Greece & 0.11 & 0.11 & 0.36 & 5,855 & 0 & 13,307 \\
\hline Ireland & 0.30 & 0.30 & 0.37 & 15,969 & 0 & 3,726 \\
\hline Luxembourg* & 0.22 & 0.22 & 0.22 & 11,710 & 0 & 0 \\
\hline Monaco* & 0.04 & 0.04 & 0.04 & 2,129 & 0 & 0 \\
\hline Netherlands* & 0.27 & 0.63 & 0.63 & 14,372 & 19,162 & 19,162 \\
\hline Portugal & 0.11 & 0.11 & 0.43 & 5,855 & 0 & 17,033 \\
\hline Sweden * & 0.20 & 0.46 & 0.46 & 10,646 & 13,840 & 13,840 \\
\hline $\begin{array}{l}\text { TOTAL } \\
(\%)\end{array}$ & & & & $\begin{array}{c}259,225 \\
100 \%\end{array}$ & $\begin{array}{l}75,053 \\
29.0 \%\end{array}$ & $\begin{array}{r}153,832 \\
59.3 \%\end{array}$ \\
\hline
\end{tabular}

${ }^{*}$ Countries in which the London Protocol came into force after May $1^{\text {st }}, 2008$. 


\section{Appendix}

Table A.1

Members of the EPC as of January 2009

\begin{tabular}{|c|l|c|l|}
\hline \hline $\begin{array}{c}\text { Date of entry into } \\
\text { the EPC }\end{array}$ & \multicolumn{1}{|c|}{ Country } & $\begin{array}{c}\text { Date of entry into } \\
\text { the EPC }\end{array}$ & \multicolumn{1}{|c|}{ Country } \\
\hline Oct 7,1977 & $\begin{array}{l}\text { Belgium, Germany, France, } \\
\text { Luxembourg, The Netherlands, } \\
\text { Switzerland, United Kingdom }\end{array}$ & Nov 1, 2000 & Turkey \\
\hline May 1,1978 & Sweden & Jul 1, 2002 & $\begin{array}{l}\text { Bulgaria, Czech Republ., } \\
\text { Estonia, Slovakia }\end{array}$ \\
\hline Dec 1, 1978 & Italy & Dec 1, 2002 & Slovenia \\
\hline May 1, 1979 & Austria & Jan 1, 2003 & Hungary \\
\hline Apr 1,1980 & Liechtenstein & Mar 1, 2003 & Romania \\
\hline Oct 1,1986 & Greece, Spain & Mar 1, 2004 & Poland \\
\hline Jan 1, 1990 & Denmark & Nov 1, 2004 & Iceland \\
\hline Dec 1,1991 & Monaco & Dec 1, 2004 & Lithuania \\
\hline Jan 1,1992 & Portugal & Jul 1, 2005 & Latvia \\
\hline Aug 1,1992 & Ireland & Mar 1, 2007 & Malta \\
\hline Mar 1,1996 & Finland & Jan 1, 2008 & Norway, Croatia \\
\hline Apr 1,1998 & Cyprus & Jan 1, 2009 & $\begin{array}{l}\text { Former Yugoslav Republic } \\
\text { of Macedonia }\end{array}$ \\
\hline \hline
\end{tabular}

Table A.2

Validation fees, early renewal fees and translation costs for the year 2003

\begin{tabular}{|c|c|c|c|c|c|c|}
\hline \multirow{2}{*}{ country } & \multicolumn{2}{|c|}{$\begin{array}{l}\text { validation fee } \\
{[\text { [Euro] }}\end{array}$} & \multicolumn{3}{|c|}{$\begin{array}{c}\text { renewal fee } \\
{\left[\text { Euro] }{ }^{*}\right.}\end{array}$} & \multirow{2}{*}{$\begin{array}{c}\text { translation } \\
\text { costs } \\
\text { [dummy] }\end{array}$} \\
\hline & fix & $\begin{array}{l}\text { page-based } \\
\text { (pages free) }\end{array}$ & year 4 & year 5 & year 6 & \\
\hline Austria & 116 & $25(5)$ & 94 & 101 & 138 & low \\
\hline Belgium & 0 & - & 45 & 60 & 75 & low \\
\hline Switzerland & 0 & - & 0 & 270 & 270 & low \\
\hline Cyprus & 87 & - & 52 & 70 & 87 & low \\
\hline Germany & 150 & - & 70 & 90 & 130 & low \\
\hline Denmark & 148 & $11(35)$ & 148 & 169 & 189 & high \\
\hline Spain & 245 & $10(22)$ & 25 & 48 & 71 & medium \\
\hline Finland & 85 & $10(4)$ & 125 & 140 & 165 & high \\
\hline France & 35 & - & 25 & 25 & 135 & low \\
\hline United Kingdom & 0 & - & 0 & 72 & 101 & low \\
\hline Greece & 299 & - & 46 & 54 & 70 & medium \\
\hline Ireland & 35 & - & 90 & 114 & 134 & low \\
\hline Luxembourg & 0 & - & 37 & 47 & 59 & low \\
\hline Monaco & 0 & - & 31 & 50 & 70 & low \\
\hline The Netherlands & 25 & - & 0 & 242 & 279 & medium \\
\hline Portugal & 91 & - & 41 & 53 & 59 & medium \\
\hline Sweden & 120 & $17(8)$ & 76 & 98 & 120 & high \\
\hline
\end{tabular}

* Source: Official Journal and the National Law Relating to the EPC; exchange rates: CA/D 1/03 
Table A.3

Country Abbreviations

\begin{tabular}{|l|c|l|c|}
\hline \hline Country & Abbreviation & Country & Abbreviation \\
\hline Austria & AT & Ireland & IE \\
\hline Australia & AU & Israel & IL \\
\hline Belgium & BE & Italy & IT \\
\hline Canada & CA & Japan & JP \\
\hline Switzerland & CH & Korea & KR \\
\hline Cyprus & CY & Luxembourg & LU \\
\hline Germany & DE & Monaco & MC \\
\hline Greece & GR & The Netherlands & NL \\
\hline Denmark & DK & Norway & NO \\
\hline Spain & ES & Portugal & PT \\
\hline Finland & FI & Sweden & SE \\
\hline France & FR & The USA & US \\
\hline United Kingdom & UK & & \\
\hline \hline
\end{tabular}

Table A.4

Dyen Matrix of Linguistic Differences (Ginsburgh et al. 2005)

\begin{tabular}{ccccccccccc}
\hline \hline & & & & & & & & & & \\
& Dk & D & E & F & G & Gr & I & Po & S & Sw \\
& & & & & & & & & \\
\hline Dk & 0 & 0.337 & 0.407 & 0.759 & 0.293 & 0.817 & 0.737 & 0.750 & 0.750 & 0.126 \\
\hline D & 0.337 & 0 & 0.392 & 0.756 & 0.162 & 0.812 & 0.740 & 0.747 & 0.742 & 0.308 \\
E & 0.407 & 0.392 & 0 & 0.764 & 0.422 & 0.838 & 0.753 & 0.760 & 0.760 & 0.411 \\
F & 0.759 & 0.756 & 0.764 & 0 & 0.756 & 0.843 & 0.197 & 0.291 & 0.291 & 0.756 \\
\hline$G$ & 0.293 & 0.162 & 0.422 & 0.756 & 0 & 0.812 & 0.735 & 0.753 & 0.747 & 0.305 \\
Gr & 0.817 & 0.812 & 0.838 & 0.843 & 0.812 & 0 & 0.822 & 0.833 & 0.833 & 0.816 \\
I & 0.737 & 0.740 & 0.753 & 0.197 & 0.735 & 0.822 & 0 & 0.227 & 0.212 & 0.741 \\
Po & 0.750 & 0.747 & 0.760 & 0.291 & 0.753 & 0.833 & 0.227 & 0 & 0.126 & 0.742 \\
S & 0.750 & 0.742 & 0.760 & 0.291 & 0.747 & 0.833 & 0.212 & 0.126 & 0 & 0.747 \\
Sw & 0.126 & 0.308 & 0.411 & 0.756 & 0.305 & 0.816 & 0.741 & 0.742 & 0.747 & 0 \\
& & & & & & & & & & \\
\hline \hline
\end{tabular}

Notes. Since Finnish is not a Indo-European language, it is not included here. Given the linguistic remoteness of Finnish, its Dyen distance to every language in the table was set to 1 . Dk = Danish, $\mathrm{D}=$ Dutch, $\mathrm{E}=$ English, $\mathrm{F}=$ French, $\mathrm{G}=$ German, $\mathrm{Gr}=$ Greek, It $=$ Italian, $\mathrm{Po}=$ Portuguese, $\mathrm{S}=$ Spanish, $\mathrm{Sw}=$ Swedish. 


\section{Table A.5}

Multivariate analysis of patent validations for 2003 (marginal effects from robust probit regression, standard errors adjusted for intra-group correlation)

\section{Coefficients of the Technical Joint Clusters (Model 5) $\mathrm{N}=862,549$}

\begin{tabular}{|c|c|}
\hline Dependent variable & \begin{tabular}{|c|} 
Model 5 \\
Validation $(0 / 1)$ \\
\end{tabular} \\
\hline \multicolumn{2}{|c|}{$\begin{array}{l}\text { EPO Industry Clusters; reference group: } \\
\text { Vehicles \& General Technology }\end{array}$} \\
\hline Industrial Chemistry & $\begin{array}{l}0.110^{* * *} \\
{[0.006]}\end{array}$ \\
\hline Organic Chemistry & $\begin{array}{l}0.317 * * * \\
{[0.006]}\end{array}$ \\
\hline Polymers & $\begin{array}{l}0.119 * * * \\
{[0.005]}\end{array}$ \\
\hline Biotechnology & $0.349 * * *$ \\
\hline Telecommunications & $\begin{array}{l}0.007 \\
{[0.006]}\end{array}$ \\
\hline Audio/Video/Media & $\begin{array}{l}0.021 * * * \\
{[0.006]}\end{array}$ \\
\hline Electronics & $\begin{array}{l}0.017 * * * \\
{[0.005]}\end{array}$ \\
\hline Electricity \& Electrical Machines & $\begin{array}{l}0.017 * * * \\
{[0.005]}\end{array}$ \\
\hline Computers & $0.014^{* *}$ \\
\hline Measuring Optics & $\begin{array}{l}0.024 * * * \\
{[0.005]}\end{array}$ \\
\hline Handling \& Processing & $\begin{array}{l}0.075 * * * \\
{[0.005]}\end{array}$ \\
\hline Civil Engineering / Thermodynamics & $\begin{array}{l}0.024 * * * \\
{[0.005]}\end{array}$ \\
\hline Human Necessities & $\begin{array}{l}0.083 * * * \\
{[0.005]}\end{array}$ \\
\hline Pseudo R2 & 0.274 \\
\hline
\end{tabular}


Table A.6

Renewal Fees by Country and Renewal Year - 2008 [EURO]

\begin{tabular}{|c|c|c|c|c|c|c|c|c|c|c|c|c|c|c|c|c|c|c|}
\hline & d & h & th & 6th & th & 8th & 9th & 10th & 11th & 12th & 13th & 14th & 15th & 16th & 17th & 18th & 19th & 20th \\
\hline $\mathrm{AT}$ & 70 & & & & & & & & & & & & & & & & & 40 \\
\hline BE & & & & & & & & & & & & & & & & & & \\
\hline $\mathrm{CY}$ & 2.7 & & & & .5 & & & 5.0 & & & & & & & & & & \\
\hline $\mathbf{K}$ & & & 88.3 & & & & & 77 & .3 & & .7 & & & & & & & \\
\hline FI & 17 & & & & & & & & 39 & & & & & & & & & \\
\hline FR & & & & & & & & & 250 & & & & & & & & 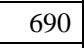 & \\
\hline DE & & & & & & & & & 4 & 6 & & & 106 & 1230 & 1410 & 0 & 1760 & 940 \\
\hline G & & & & & & & & & & & & & & & & & & \\
\hline IE & 6 & & & & & & & & 2 & & & & & & & & & 08 \\
\hline $\mathbf{L U}$ & & & & & & & & & & & & & & & & & & \\
\hline MC & 32 & & & & & & & & 1 & 95 & & & & 0 & 0 & & 5 & 55 \\
\hline NL & & & & & & & & & & & & & & 1000 & 00 & 0 & 00 & \\
\hline $\begin{array}{l}\mathbf{P T} \\
\end{array}$ & & & & & 3.4 & .5 & & 1.7 & 201.5 & 28.9 & 74.7 & 20.5 & 66.3 & 1 & \begin{tabular}{|l|l}
457.9 \\
\end{tabular} & 7 & 49.5 & 59 \\
\hline ES & 22 & & & & 3.3 & 28.6 & & 179.0 & 216.9 & 254.7 & 292.4 & & .2 & .7 & 4699.1 & & 70.0 & 520.4 \\
\hline SE & 6.3 & & 93. & 114.1 & 0.1 & 166.0 & 19 & 233.5 & 259.4 & 280.2 & 295.7 & 316.5 & 342.4 & 368.3 & \begin{tabular}{|l|l}
394.3 \\
\end{tabular} & 420.2 & 46.2 & 466.9 \\
\hline $\mathbf{C H}$ & 0 & & & & 30.7 & & 202.6 & 202.6 & 202.6 & 202.6 & 202.6 & 202.6 & 202.6 & 202.6 & 202.7 & 202.6 & 02.6 & 202.6 \\
\hline UK & 0 & 0 & 67.0 & & 20.6 & 147.4 & & 201.6 & 227.8 & 254.6 & 281 & 308.2 & 335.0 & 36 & 402.0 & .2 & 482.4 & 536.0 \\
\hline IT & 0 & 0 & 60 & & 120 & 170 & 200 & 230 & 310 & 410 & 530 & 600 & 650 & 650 & 650 & 650 & 650 & 650 \\
\hline
\end{tabular}

* Source: http://www.epo.org/patents/law/legal-texts/html/natlaw/en/vi/index.htm 